\title{
Curricular Recommendations for a National Family Medicine Subinternship: A Qualitative Analysis From Multiple Stakeholders
}

Maria Syl D. de la Cruz, MD; Tomoko Sairenji, MD, MS; Sarah E. Stumbar, MD, MPH; Dolapo Babalola, MD; Alexander W. Chessman, MD

\begin{abstract}
BACKGROUND AND OBJECTIVES: The 2011 Alliance for Clinical Education panel recommended the development of a specialty-specific curriculum for all subinternships (sub-ls). A 2019 CERA survey found that $58 \%$ of family medicine clerkship directors agreed that a standardized curriculum would be helpful. The goal of this study was to explore attitudes and preferences regarding a national family medicine sub-I curriculum among a broad set of stakeholders.

METHODS: Focus groups were conducted with medical students, residents, residency faculty, and undergraduate medical education faculty at the 2020 STFM Conference on Medical Student Education. Focus groups were transcribed, and a qualitative analysis was conducted with participants' responses about the benefits and characteristics of a family medicine sub-l, recommendations for core sub-I skills/objectives, likelihood of using a national curriculum, and preferred student and program evaluation methods.
\end{abstract}

RESULTS: There were four focus groups with a total of $\mathbf{2 4}$ participants. The following main themes emerged: the family medicine sub-l has distinctive characteristics from other sub-ls and provides unique benefits for students and residency programs, a standardized curriculum should allow for adaptability and flexibility, and the sub-l evaluation for the students and program should be specific and experience-focused. These themes were classified into specific subthemes.

CONCLUSIONS: The stakeholder emphasis on themes of uniqueness, adaptability, and specificity within evaluation will help educators structure a comprehensive framework for national recommendations for the sub-I curriculum. A well-designed family medicine sub-I may provide rigorous educational training for students and may also encourage career commitment to the discipline.

(Fam Med. 2021;53(10):835-42.)

doi: 10.22454/FamMed.2021.567515

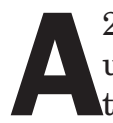
2011 Alliance for Clinical Education panel recommended that all specialties develop specific curriculum for subinternship (sub-I) experiences during the fourth year of medical school. ${ }^{1}$ National standards and resources can help individual schools by providing an already-constructed core curriculum designed to prepare students well for residency training, and help residency programs more accurately predict the baseline competence of their interns. The Association of Program Directors and Clerkship Directors in Internal Medicine, the Council on
Medical Student Education in Pediatrics, and the Association of Pediatric Program Directors developed sub-I guidelines for internal medicine and pediatrics, respectively. ${ }^{2,3}$ The Society of Teachers of Family Medicine (STFM) has developed multiple iterations of a National Clerkship Curriculum - a renewable, web-based, peer-reviewed resource for the third-year core clerkshipbut there is not yet a national standard for the sub-I rotation. ${ }^{4}$

In previous studies, residents and faculty identified the sub-I as one of the most important rotations to prepare a student for internship. ${ }^{2,5-6}$ Specifically, the family medicine sub-I would prepare students to be interns by fostering progressive responsibility for patient care, solidify career choice and provide networking opportunities, integrate medical school and residency program outcome measures, and emphasize the values, principles, and

From the Department of Family and Community Medicine, Thomas Jefferson University, Philadelphia, PA (Dr de la Cruz); Department of Family Medicine, University of Washington, Seattle, WA (Dr Sairenji); Department of Humanities, Health, and Society, Herbert Wertheim College of Medicine, Florida International University, Miami, FL (Dr Stumbar); Department of Clinical Family Medicine, Morehouse School of Medicine, Atlanta, GA (Dr Babalola); and Department of Family Medicine, Medical University of South Carolina, Charleston, SC (Dr Chessman). 
unique aspects of family medicine. A national curriculum for the family medicine sub-I would enable the specialty to achieve parity with and rigor equivalent to other disciplines while also ensuring resources comparable to those available for the core clerkship experience.

In 2019, STFM convened a task force to develop national curricular recommendations for the family medicine sub-I. Task force members included a broad constituency, with representation of student and resident learners as well as undergraduate (UME) and graduate medical education (GME) faculty. Representing the first publication on this issue, the task force's 2019 CERA survey of family medicine clerkship directors found that $84 \%$ of responding schools required a sub-I in any discipline-including but not limited to family medicine. Furthermore, 58\% of clerkship directors felt that national guidance and standards for the family medicine sub-I would be helpful. ${ }^{7}$ While the CERA study provided useful background information, it was limited only to an assessment of clerkship directors' attitudes and constrained by its 10-item, closed-ended item survey format. Thus, the task force planned and conducted a set of focus groups consisting of UME and GME educators, residents, and students at the 2020 STFM Conference on Medical Student Education. The resulting qualitative analysis, presented here, allowed for a more in-depth understanding of this broad set of stakeholders' attitudes and preferences regarding a national family medicine sub-I curriculum.

\section{Methods}

\section{Setting and Participants}

Authors conducted semistructured focus groups with medical students, residents, GME faculty, and UME faculty at the 2020 STFM Conference on Medical Student Education. The Family Medicine Sub-I Task Force invited participants to the focus groups through an email posted to the STFM MSE Collaborative listserv. One focus group was conducted over a breakfast session and included students, UME and GME educators. The remaining three focus group included a group each of students, UME educators, and GME educators. All focus groups were 60 minutes long. Participation was voluntary, and no compensation was provided. All participants gave verbal informed consent prior to starting the focus group. The Human Subjects Division at the University of Washington reviewed this study and determined it exempt (IRB ID: STUDY00009181).

\section{Data Collection}

Two task force members facilitated each focus group: one faculty member and one student, to minimize bias. Facilitator pairs and participants were combined to ensure that there was no preexisting relationship. For preparation, facilitators used a guide with facilitator tips and standard questions (Table 1) developed by consensus. Questions explored the benefits and characteristics of existing and ideal family medicine sub-Is, recommendations for core goals and objectives in a standardized national curriculum, likelihood of using a standardized national sub-I curriculum, and preferred evaluation methods of both students and the sub-I curriculum.

\section{Data Analysis}

A commercial transcription service transcribed the individuallyrecorded focus group sessions. Each

Table 1: Focus Group Questions From the 2020 STFM Medical Education Conference

1. What are the benefits of a family medicine (FM) subinternship (sub-I)?

- For students? For med schools? Departments? Residency programs? The specialty of family medicine? Other stakeholders?

2. How is an FM sub-I unique from other specialty sub-Is?

- Share a story about what symbolizes or encapsulates a good FM sub-I experience.

- What makes a FM sub-I a FM sub-I?

- What should be part of every FM sub-I?

- What, if missing, would change a FM sub-I from being specifically family medicine?

3. What needs does a FM sub-I fulfill from your standpoint? (as a student, UME/GME faculty, other?)

4. How do you think a FM sub-I impacts career decisions for students?

- Tell me about the tensions between:

- The Sub-I is intended to prepare a student to be ready to function as a fully competent intern.

- The Sub-I is intended as an audition: so the student is ranked higher as an applicant to the residency program hosting the Sub-I, and so the residency program is ranked higher by the student.

5. What are your thoughts on creation of a national standardized curriculum for FM sub-I?

6. How should students be evaluated on a sub-I? (Show them the Entrustable Professional Activities [EPA] list)

- What are your thoughts on using these for evaluation?

- What is missing from this list that a FM-bound student should have?

7. What skills or clinical experiences should be included in an FM sub-I?

8. We have discussed about FM sub-Is. Are there any comments or thoughts that we have missed? 
focus group facilitator pair-reviewed transcripts to confirm accuracy. All members of the authorship team were assigned to each review one transcript, independently identify emerging themes, and count theme frequency. One author (M.D.) used a content analysis approach ${ }^{8}$ to create an initial codebook based on the consistency of themes across groups. An authorship subgroup (M.D., T.S., D.B.) met via Zoom three times to revise the coding scheme and finalize four main themes, which were broken down into subthemes. Transcripts were reread independently to compare codes on an ongoing basis, add new codes where necessary, and discuss codes until there was universal consensus. All data management, coding, and analysis was done manually.

\section{Results}

Participant Characteristics

There were a total of 24 participants in four focus groups: six GME educators in the GME group, five UME educators in the UME group, five students in the student group, and eight in the breakfast session with a variety of participants (one GME faculty, three UME faculty, two subI administrative staff, two students).

\section{Perspectives on a Family} Medicine Sub-I Among Multiple Stakeholder Groups

Four main themes emerged during the focus groups. Each theme identified core characteristics, benefits, and evaluation preferences of a family medicine sub-I, which then would inform the content of a standardized national sub-I curriculum. Each of these themes had subthemes, with representative quotations supporting them (Table 2).

Theme 1: The Family Medicine sub-I Has Unique Characteristics That Set It Apart From Other Clerkships and Subinternships. Many of the focus group participants identified that it is valuable for the family medicine sub-I to expose students to a broad patient population (ie, children, pregnant women, adults, older adults) while also teaching the diagnosis and management of a variety of problems and diagnoses. This is a key distinguishing feature of the family medicine sub-I from other subIs. The participants observed that their family medicine attendings on the sub-I placed an emphasis on social justice, the social determinants of health, and community medicine,

Table 2: Quotations From Focus Group Participants Regarding the Four Themes and Subthemes Related to Family Medicine Subinternship Curricular Recommendations

\begin{tabular}{|c|c|}
\hline Themes & Representative Quotations \\
\hline \multicolumn{2}{|c|}{ Theme 1: The Family Medicine sub-l has unique characteristics that set it apart from other clerkships and sub-ls. } \\
\hline $\begin{array}{l}\text { Subthemes: } \\
\text { 1. Broad patient } \\
\text { population (pediatrics, } \\
\text { OB, adult), } \\
\text { management of variety } \\
\text { of problems/diagnoses }\end{array}$ & $\begin{array}{l}\text { "I had a student tell me...'You guys just don't refer as much.' She goes, 'Internal medicine if } \\
\text { somebody has chest pain, they go to cardiology. If they've abdominal pain, they go into surgery } \\
\text { or GI.' She goes, 'You guys don't do that.' It was really eye-opening to her." -Medical school } \\
\text { faculty } \\
\text { "So what's the difference between a family medicine sub-I and an internal medicine sub-I? I } \\
\text { think it is critical to say that we should provide exposure to the sub-I to the full scope of family } \\
\text { medicine." - Residency faculty }\end{array}$ \\
\hline $\begin{array}{l}\text { 2. Focus on social } \\
\text { justice, social } \\
\text { determinants of health } \\
\text { and community health }\end{array}$ & $\begin{array}{l}\text { "I think also what I hear a lot from people who are interested in family medicine is the } \\
\text { community and the mission focus. I think that's one of the things that I've noticed residencies } \\
\text { really highlight is these are the things that they're doing that set them apart from other } \\
\text { residencies, and that's what's going to draw me to that program. One of the sub-Is I did had me } \\
\text { spend a day in their rural outreach clinic, and spend a day going through their pediatric youth } \\
\text { detention centers. Seeing the under-served populations that they're trying to reach out to, really } \\
\text { set it apart from some of the other sub-Is." -Student }\end{array}$ \\
\hline $\begin{array}{l}\text { 3. Continuity of care } \\
\text { and longitudinal } \\
\text { relationships/family- } \\
\text { centered }\end{array}$ & $\begin{array}{l}\text { "I just wanted the longitudinal [component]... I wanted to find out what happened to [patients] } \\
\text { when they got discharged or the physician would do seven on, seven off and then on the } \\
\text { seventh day I was like, 'But you have } 12 \text { patients here that you have no idea what's going to } \\
\text { happen to them.' That bothered me. The continuity of care was a major piece." -Student }\end{array}$ \\
\hline $\begin{array}{l}\text { 4. FM culture and } \\
\text { personality }\end{array}$ & $\begin{array}{l}\text { "What the students see is a different style of management [from IM]. That's the big difference. } \\
\text { So they see the same patients and what they say is, the quality of management is the same, } \\
\text { the style of management is different. Internal medicine does their migratory group rounds, } \\
\text { and it's very lockstep, very formal. Family medicine is much more informal. It would be kind } \\
\text { of asynchronous. Like the faculty member may see one with the student, and they'll break off } \\
\text { and do something else, and they'll pair up with someone else and do it. So it's not just lockstep, } \\
\text { point to point. It's much more informal, let's get the work done, let's collaborate, let's all team } \\
\text { up, rather than everything has to go as pods around and be this formal. So that's the biggest } \\
\text { difference. The students tend to really like that informality and the focus on, let's do whatever } \\
\text { it takes to get it done and let's just be comfortable with each other's preferences. So it's a flavor } \\
\text { rather than a substance." } \\
\text {-Medical school Faculty }\end{array}$ \\
\hline
\end{tabular}

(Continued on next page) 
Table 2: Continued

\begin{tabular}{|c|c|}
\hline \multicolumn{2}{|c|}{ Theme 2: There are unique benefits of a family medicine sub-l from a student and residency program perspective. } \\
\hline \multicolumn{2}{|r|}{ Student Perspective } \\
\hline $\begin{array}{l}\text { Subthemes: } \\
\text { 1. Solidify/affirm } \\
\text { interest in FM }\end{array}$ & $\begin{array}{l}\text { "The importance of doing a family medicine sub-I and doing it early is just to double-check } \\
\text { yourself on, like, 'I feel this, I think this is true, and this is what I want to do with my life.' I'll } \\
\text { get the most insider look into what an internship is going to be like and what your life is going } \\
\text { to be like for the next three years and then beyond that." } \\
\text {-Student }\end{array}$ \\
\hline $\begin{array}{l}\text { 2. Evaluate the fit of } \\
\text { the program }\end{array}$ & $\begin{array}{l}\text { "I did rural and urban sub-Is just to see. That was impactful for me because then I definitely } \\
\text { applied to way more rural programs because I discovered that I enjoyed that type of training } \\
\text { better." } \\
\text {-Student }\end{array}$ \\
\hline $\begin{array}{l}\text { 3. Increase autonomy } \\
\text { and responsibility, } \\
\text { and learning skills, } \\
\text { limitations and when } \\
\text { to ask for help }\end{array}$ & $\begin{array}{l}\text { "My sub-I was totally outpatient because we had such an extensive inpatient experience } \\
\text { throughout all third-year, that if you picked the family medicine sub-I, it was all outpatient. But } \\
\text { what I got was tons of responsibility. That let me bond and understand what family physicians } \\
\text { do and feel more confident." -Student } \\
\text { "I think it also gives students an opportunity to have a sense of increased autonomy, hopefully } \\
\text { and see like what is it actually like to do this. Because I think there's a big difference between } \\
\text { what they see on third year and their level of responsibility... when they're the ones trying to } \\
\text { make the decisions. That feels different to a learner I think." - Student } \\
\text { "One of my sub-Is, I had my own schedule with my own patients, which was really nice to just } \\
\text { take on that next level of ownership of, "These are my patients, I have to stay on time and get } \\
\text { all of my things done." -Student }\end{array}$ \\
\hline $\begin{array}{l}\text { 4. Strengthen } \\
\text { residency application } \\
\text { to residency }\end{array}$ & $\begin{array}{l}\text { "One thing I'm hoping to get on my sub-I is a foot in the door in that residency." } \\
\text {-Student }\end{array}$ \\
\hline $\begin{array}{l}\text { 5. Build network for } \\
\text { career development }\end{array}$ & $\begin{array}{l}\text { "I think part of that too is meeting mentors and seeing one, the career trajectory, but two, } \\
\text { people who actually encourage you. Writing letters, meeting mentors, and then you get } \\
\text { connected to projects, to conferences, to other People with similar interests. That's huge I think } \\
\text { is a big part of the whole process of career development." -Student }\end{array}$ \\
\hline $\begin{array}{l}\text { 6. Decide future scope } \\
\text { of practice by seeing } \\
\text { multiple aspects of FM }\end{array}$ & $\begin{array}{l}\text { "I think it also was helpful to get exposed to different attendings who had different niches } \\
\text { within their program, and within their own career, and get exposed to different ways family } \\
\text { medicine could go. That informed how I want to choose programs. Once I realized that I'm more } \\
\text { interested in doing OB, and that I like a certain attending career, I think, Well how did they get } \\
\text { there, and how can I get there?" -Student }\end{array}$ \\
\hline \multicolumn{2}{|r|}{ Residency Program Perspective } \\
\hline $\begin{array}{l}\text { Subthemes: } \\
\text { 1. Exposure to } \\
\text { students to promote/ } \\
\text { advertise their } \\
\text { program }\end{array}$ & $\begin{array}{l}\text { "This past year we had the opportunity to have a student from a school that doesn't have a } \\
\text { family medicine department, so this was the only exposure to what comprehends a full scope } \\
\text { family medicine, what that looks like and so that was able to take that back to his home } \\
\text { institution and invite more... I think that's big to spread the gospel that that's family medicine." } \\
\text {-Residency faculty }\end{array}$ \\
\hline $\begin{array}{l}\text { 2. Evaluate students } \\
\text { for fit }\end{array}$ & $\begin{array}{l}\text { “...knowing whether or not an applicant, she's a good fit for our program” } \\
\text {-Residency faculty }\end{array}$ \\
\hline $\begin{array}{l}\text { 3. Evaluate students' } \\
\text { progression from } \\
\text { observer to intern and } \\
\text { across settings (ie, } \\
\text { inpatient, outpatient, } \\
\text { labor and delivery, etc) }\end{array}$ & $\begin{array}{l}\text { "From an education side, I think there is a gap between when you get in your third year and } \\
\text { the expectations on July first. I think that in developmental stage there does need to be this } \\
\text { place where you are closely supervised but still have a lot more autonomy than you would as a } \\
\text { third-year student. Because in a lot of places it's not then if you're halfway smart, particularly } \\
\text { if you know how to play your faculty residents, you don't really have to make any decisions. You } \\
\text { can say facts but never really put your knuckle down. People are actually getting pretty good at } \\
\text { that after so many years of education." -Residency faculty }\end{array}$ \\
\hline \multicolumn{2}{|c|}{ Theme 3: The family medicine sub I should follow a standardized curriculum, but adaptability and flexibility are important. } \\
\hline $\begin{array}{l}\text { Subthemes: } \\
\text { 1. Common language } \\
\text { and expectations while } \\
\text { allowing for individual } \\
\text { program flexibility }\end{array}$ & $\begin{array}{l}\text { "I think it may be helpful in creating a common language and helping students know what } \\
\text { to expect as long as it is a framework that allows for this individual variance across different } \\
\text { programs." -Residency faculty } \\
\text { "One of my big concerns with creating a standardized curriculum is that it will be too rigid for } \\
\text { each program. Even just doing three or four sub-Is, we've all experienced how different they } \\
\text { are, and how they have different things that they include, and maybe they can't do OB. That's a } \\
\text { really great way to make it flexible for all those programs." -Student }\end{array}$ \\
\hline
\end{tabular}


Table 2: Continued

2. Different clinical settings-outpatient and inpatient, labor and delivery, newborn nursery, etc

\section{FM educational} topics geared toward program strengths (inpatient, OB, pediatrics, procedures, practice management, social determinants)

4. Opportunities for different tracks based on student interest and capacity

5. Competencies that students should be able to fulfill through the sub-I capacity

6. Limitations to standardized curriculum include location, faculty number, number of learners, time, systems, diversity of experiences
"I think well, for me, it has to include pediatric care and Ob-Gyn, otherwise it's internal medicine in my case, that's how I see it. Because when we have the students come to us and they say, 'Oh, are we going to do a pap smear?' 'Yes, we're going to do a pap smear.' It's like, 'Oh, okay, yes, this is family medicine. We do women's health. We do pediatric care.' I think those two elements are essential in a sub-internship experience in my opinion." -Residency faculty

"If you give them resources so that they can teach hands-on in the clinic, whether that be in a four week curriculum, you have a tentative schedule where there's one day you talk about blood pressure management. I really see residents especially trying to learn with the educators, and giving them tools so they don't have to be creative on the fly. Then the rotation is more comprehensive. It doesn't just depend on who I work with, someone who teaches well this afternoon, but this morning I worked with somebody who it's not their forte, or something that feels comfortable. I see that being a way to teach in the clinic more comprehensively, and then giving people the ability to fill the gaps with modules or some resource. I think that'd be really useful." -Student

"I feel like - and we kind of talked about tracks- that we might not have one perfect family medicine experience. I think what you just said is the principle or the value of family medicine sub-I that the context of the how and the structure is what you're talking about. I feel like you could have different tracks. We could have track A, which is the ideal, you're doing everything, the pluripotent family medicine, stem cell sub-I. But then we could have these other versions of it just like they do with the third-year National Clerkship Curriculum and you could take what you can." -Focus group participant

"So if we're looking at some internships where these students are supposed to be acting like interns, can we pull some of the information from that internship year evaluation? That's the level that we're being held to as a sub intern. Rather than we reinvent the wheel, we can go get those competencies and the things that an intern is expected to do and compare it with the sub-I." -Student

"Some people want to do full spectrum care and in rural Wyoming where they're doing surgical obstetrics and stuff like that, or they want to work in the inner city and only do Suboxone therapy, or only do LGBTQ + transition stuff. It's so hard to capture that in one four week period." -Student

Theme 4: The Family Medicine sub-l evaluation should include components specific to the experience.

Subthemes:

1. Skills such as order entry, calling consults, note writing, admissions, transitions of care

2. Use of EPAs to evaluate specific skill sets (higher level skills, preventive care)

3. Direct observation and summative and formative feedback

4. Student evaluation of the sub-I
"I don't like computers, so being able to navigate the system, and to submit those orders, and how to go through the admission process, and the discharge process on the computer, I think fourth year sub-Is are where you learn how to do that."

-Student

"We do like that idea of a just-in-time evaluation. That's an activity that's real life. Like if they're acting as interns, they should be giving oral presentations, or writing orders." -Student

"I think you could do something really cool with [what you're saying about a] RIME and the EPAs. You could put together a pilot of and ask people across the country, where do you think sub-Is should be? Because in my mind, sub-Is are really- they should be able to do the problem with the interpreter part and they should be able to start managing a real thing. Especially, for simple cases." -Medical school faculty

"You have instant feedback. That goes into your final eval and the numbers work out for grading and stuff like that. But the culture at our institution is that written evals get done in real-time and given back to the students and the student uploads them for their grade." -Student

"I feel like having the students evaluate the sub-Is, as you were saying before, because the schools have to hold the sites accountable for like if they get a form that says this is what you need to do as a sub-I for family medicine, and they're like, 'Yes, sure. We'll do that.' And then they're having to students shadow, somebody needs to block students from knowing that. Because we don't know ahead of time, and then we show up and we're like, 'Oh, my gosh, I am wasting a month of my life here at this site shadowing.' Especially after such a holistic experience, going into that makes that so depressing." -Student 
which was distinctive from their experiences on non-family medicine rotations. Participants also witnessed the continuity of care and familycentered longitudinal relationships through the provider-patient relationships of attendings and residents, while on the family medicine sub-I. Additionally, focus group members remarked on the culture and personality of family physicians who teach on the sub-I, which contributed to the distinctive experience. By exposing students on the FM sub-I to the specialty's unique characteristics, this could help not only solidify their career choices but also build the skills and knowledge that they would need to be future family physicians. From a curriculum development standpoint, it is important to ensure that these unique characteristics are represented in a national FM sub-I curriculum.

Theme 2: There Are Unique Benefits of a Family Medicine Sub-I From a Student and Residency Program Perspective. From a student standpoint, completion of a family medicine sub-I affirmed a student's interest in the specialty and helped to evaluate the potential fit of a residency program. Participants described this rotation as a critical opportunity for students to gain autonomy and responsibility, learn their skills' limitations, and identify when to ask for help. A family medicine sub-I helped students with their residency application, provided an opportunity for a letter of recommendation, and helped them to build a network for career development. Students also felt that the family medicine sub-I helped them to explore future scope of practice by seeing multiple aspects of the field, such as inpatient, outpatient, pediatrics, women's health/obstetrics, procedures, sports medicine, etc. This broad exposure set the family medicine sub-I apart from sub-Is in other disciplines.

From a residency program perspective, a sub-I promoted and advertised the residency program and gave the program an opportunity to evaluate future applicants for fit. Residency faculty participants described the importance of the subI in allowing for the evaluation of students' progression from observer to intern across a variety of settings (ie, inpatient, outpatient, labor and delivery, newborn nursery). A standardized curriculum would provide a framework for skill development and assessment of the sub-I learners as they progress during the rotation and across these multiple settings.

Theme 3: The Family Medicine Sub-I Should Follow a Standardized Curriculum, but Adaptability and Flexibility are Important. The majority of the focus group participants felt that the family medicine sub-I curriculum should not only foster common, specialty-specific language and expectations but also allow for individual program flexibility. While the sub-I should expose students to as many different clinical settings as possible, the educational focus of the family medicine sub-I should draw upon a program's strengths, including inpatient, obstetrics, pediatrics, procedures, practice management, or community health. A couple of participants suggested that the sub-I curriculum could provide different tracks based on the strengths and capacity of the program, as well as student interest.

While there should be a standardized set of competencies that students can demonstrate after completion of a family medicine sub-I, participants recognized that the ability to teach these competencies may be influenced by the specifics of program location/region, number of faculty and learners, time, health system characteristics, resources, and/or diversity of clinical experiences. A few participants suggested that educational modules may assist students in supplementing their learning with topics that they did not have direct clinical exposure to during the sub-I.
Theme 4: The Family Medicine Sub-I Assessment Should Include Components Specific to the Experience. Participants expressed that the family medicine sub-I assessment of students should include tasks such as order entry, calling consults, patient documentation, admissions, transitions of care, and discharge planning. These core skills should be evaluated for an individual sub-I learner, and this evaluation should be included as part of a standardized FM sub-I curriculum. Furthermore, the AAMC's Entrustable Professional Activities (EPAs) ${ }^{9}$ could be used to evaluate specific higher-level skill sets by facilitating direct observation and for providing summative and formative feedback. Focus group members also recommended that the standardized sub-I curriculum include a programmatic evaluation, which would be completed by students at its conclusion and provide questions specifically related to experiences necessary to achieve the course's core competencies. This evaluation of the family medicine sub-I would help the task force to refine and revise the content and structure of a national family medicine sub-I curriculum in the future.

\section{Discussion}

The identified themes from the focus groups convened at the 2020 STFM Conference on Medical Student Education provided robust information regarding defining and essential characteristics of the family medicine sub-I, as well as suggestions for a national curriculum. A national family medicine sub-I curriculum would embrace the field's unique characteristics and principles, allowing students not only to reaffirm their interest in the specialty but also imagine their ideal, future scope of care. In a previous study ${ }^{7}$ higher match rates in family medicine were positively associated with a sub-I requirement and with having a family medicine sub-I at a residency site. This association argues for the importance of having a family medicine sub-I, particularly 
at a residency site, to help reach the American Academy of Family Physicians' goal of $25 \%$ of medical school seniors selecting family medicine as their specialty by $2030 .{ }^{10}$

Previous studies identified the skills of time management and prioritization, effective communication, and knowing when to ask for help as the most important on a sub-I; each of these is highlighted as a key focus of the pediatrics and internal medicine national sub-I curricula. , $^{2,3,6,11}$ While our focus group participants agreed that recognizing limitations and when to ask for assistance are important skills, they emphasized that the principle of student autonomy should be reflected in a standardized sub-I curriculum. It is essential that students take ownership of patient care responsibilities so that they can build the clinical and communication skills necessary for patient management. If a subI is considered one of the best preparatory courses for internship, $, 5,5$ then students need to practice the skills of prioritization, organization, and communication independently in a safe and supportive environment. A sub-I is the ideal rotation to give the student the independence to place orders and write prescriptions, write notes/discharge summaries, talk with and educate patients, communicate with consultants, and discuss care with the interprofessional team, while still under the direct supervision of residents and attendings. A standardized sub-I curriculum should include these core skills for residency preparation as well as place an emphasis on autonomy.

Similarly to the internal medicine and pediatrics curricula, a national family medicine sub-I curriculum should incorporate direct assessment of these higher-order sub-I skills. ${ }^{2,3}$ Our study participants supported direct observation as integral to student feedback, which has been shown in prior studies to allow for identification of educational deficiencies. ${ }^{12,13}$ Focus group participants also felt that the Entrustable Professional Activities (EPAs) ${ }^{9}$ may provide a framework for these higher-order sub-I skills assessments, which are also incorporated into the internal medicine sub-I curricula. ${ }^{2}$ A national family medicine subinternship curriculum will present a useable assessment framework and rubrics for the individual learner and the sub-I course, based on the EPAs, that can be adapted to a variety of patient care settings.

A standardized national sub-I curriculum with resources would benefit medical schools by providing an existing framework for a core curriculum designed to prepare students for residency; this core curriculum could also help residency programs more accurately assess their interns' baseline competency. A national family medicine sub-I curriculum should include broad course objectives and experiences, which are focused on the core principles and skills of family medicine and may be easily adapted based on specific program resources. As such, the sub-I curriculum must highlight that the course should be taught by family physicians who embrace the core principles of the specialty, including social justice, the social determinants of health, and longitudinal and continuity of care. While all family medicine sub-Is should be built on the core principles central to the STFM National Clerkship Curriculum, our study supports the idea that a national curriculum should allow for flexibility in the specifics of its clinical structure and focus, as family medicine is practiced very differently across the country. Ideally, the sub-I should include exposure to at least two different clinical settings, such as outpatient clinics, inpatient wards, labor and delivery, and newborn nursery, whenever possible. However, these opportunities may be limited depending on the specific program. Therefore, interactive modules or cases may be used to fill any educational gaps.

There are several limitations to this study. First, as the analysis was conducted at a family medicine conference, focus group participants were more likely to be highly motivated educators and students likely to pursue family medicine. Selection bias may have influenced our results and could limit the generalizability of our findings. Additionally, while the identified themes provide a context and general framework for the specific competencies, learning objectives and assessment tools were not reviewed. While we discussed the importance for consistency between focus group leads, slight differences in interviewing styles may have influenced participants' responses. Also, since medical educators could be difficult to identify, our recruitment through known communities of educators at each institution may have affected our sample of participants, thus resulting in sampling bias.

In conclusion, our findings revealed helpful recommendations for the development of a national family medicine subinternship curriculum. From the viewpoint of important stakeholders, these results aim to create a comprehensive framework for a standardized curriculum. The establishment of a family medicine sub-I curriculum is an opportunity to provide rigorous educational training for students, and at the same time, may support and encourage the growth of family medicine as a specialty.

FUNDING STATEMENT: This project received financial support from the Society of Teachers of Family Medicine.

CORRESPONDING AUTHOR: Address correspondence to Dr Maria Syl de la Cruz, 1015 Walnut Street, Suite 401 Curtis, Philadelphia, PA 19107. 215-503-3461. Fax: 215-955-8600. MariaSyl.delaCruz@jefferson.edu.

\section{References}

1. Reddy ST, Chao J, Carter JL, et al. Alliance for clinical education perspective paper: recommendations for redesigning the "final year" of medical school. Teach Learn Med. 2014;26(4):420-427. doi:10.1080/10401334.2 014.945027

2. Vu TR, Angus SV, Aronowitz PB, et al; CDIMAPDIM Committee on Transitions to Internship (CACTI) Group. The internal medicine subinternship-now more important than ever: a joint CDIM-APDIM position paper. J Gen Intern Med. 2015;30(9):13691375. doi:10.1007/s11606-015-3261-2 
3. The Council on Medical Student Education in Pediatrics and Association of Pediatric Program Directors. Pediatric Subinternship Curriculum. 2009. Accessed November 2 , 2020. https://media.comsep.org/wp-content/ uploads/2019/01/30172802/COMSEP-APPDF.pdf

4. National Clerkship Curriculum, 2nd ed. Society of Teachers of Family Medicine. 2018. Accessed November 2, 2020. https://www. stfm.org/teachingresources/curriculum/nationalclerkshipcurriculum/overview/

5. Lyss-Lerman P, Teherani A, Aagaard E, Loeser H, Cooke M, Harper GM. What training is needed in the fourth year of medical school? Views of residency program directors. Acad Med. 2009;84(7):823-829. doi:10.1097/ ACM.0b013e3181a82426

6. Pereira AG, Harrell HE, Weissman A, Smith CD, Dupras D, Kane GC. Important skills for internship and the fourthyear medical school courses to acquire them: a national survey of internal medicine residents. Acad Med. 2016;91(6):821826. doi:10.1097/ACM.0000000000001134
7. Sairenji T, Stumbar SE, Garba NA, et al Moving toward a standardized national family medicine subinternship curriculum: results from a CERA Clerkship Directors Survey. Fam Med. 2020;52(7):523-527. doi:10.22454/FamMed.2020.209444

8. Hsieh HF, Shannon SE. Three approaches to qualitative content analysis. Qual Health Res. 2005;15(9):1277-1288. doi:10.1177/1049732305276687

9. The Core Entrustable Professional Activities (EPAs) for Entering Residency. Association of American Medical Colleges. Accessed November 2, 2020. https://www.aamc.org/ what-we-do/mission-areas/medical-education cbme/core-epas.

10. Porter S. AAFP Hosts Launch of $25 \mathrm{x}$ 2030 Student Choice Collaborative. 2018. Accessed January 30, 2019. https://www. aafp.org/news/education-professionaldevelopment/20180905twentyfiveby2030. html

11. Angus S, Vu T, Halvorsen AJ, et al. What skills should new internal medicine interns have in July? A national survey of internal medicine residency program directors. Acad Med. 2014;89:432-435.
12. Cydulka RK, Emerman CL, Jouriles NJ; The Council on Medical Student Education in Pediatrics and Association of Pediatric Program Directors. Pediatric Subinternship Curriculum. 2009Cydulka RK, Emerman CL,Jouriles NJ. Evaluation of resident performance and intensive bedside teaching during direct observation. Acad Emerg Med. 1996;3(4):345-351. doi:10.1111/j.1553-2712.1996.tb03448.x

13. Li JT. Assessment of basic physical examination skills of internal medicine residents. Acad Med. 1994;69(4):296-299. doi:10.1097/00001888-199404000-00013 